\title{
A importância da Amazônia para a defesa e a segurança da América do Sul
}

The Importance of Amazon to the South America Defense and Security

João Estevam dos Santos Filho ${ }^{1}$

\section{RESUMO}

O objetivo do presente artigo é analisar de que maneira a região amazônica é importante para a segurança e a defesa da América do Sul. Conclui-se que a sua importância vem do fato de que é a região mais propensa a sofrer uma invasão ou guerra proxy, além de estrategicamente ser a mais bem posicionada para ajudar a garantir a integração sulamericana.

Palavras-chave: Amazônia; segurança; integração regional.

\begin{abstract}
The objective of this paper is to analyze in which way the Amazon region is important to the South America security and defense. We conclude that its importance comes from the fact that it is the region most inclined to suffer an invasion or a proxy war and strategically better positioned to help to guarantee the south-american integration.
\end{abstract}

Keyword: Amazon; Security; Regional Integration.

\section{Introdução}

O objetivo do presente artigo é analisar de que maneira a região amazônica impacta as dinâmicas securitárias e de defesa do subcontinente sul-americano como um todo. Ao longo do artigo, supõe-se uma relação direta da Amazônia com a segurança² e a defesa $^{3}$ da América do Sul e indireta com a integração infraestrutural do subcontinente.

\footnotetext{
${ }^{1}$ Graduando em Relações Internacionais pela Universidade Federal do Rio Grande do Sul, Porto Alegre, Brasil.

2 Neste trabalho, o conceito de segurança é o utilizado por Eugênio e Diniz (1998), segundo os quais "uma situação que permita aos cidadãos e às sociedades o estabelecimento de laços estáveis, quer do ponto de vista cultural (...), quer do ponto de vista comercial" (EUGÊNIO; DINIZ, 1998, p. 55).

${ }^{3}$ No presente trabalho, a definição de defesa é também a utilizada por Eugênio e Diniz (1998), segundo os quais é o "conjunto das ações militares visando garantir o estado de segurança" (EUGÊNIO; DINIZ, 1998, p. 55).
} 
Essas relações advêm do fato de a Pan-Amazônia ${ }^{4}$ ser a região da América do Sul mais propensa a sofrer uma invasão territorial por parte de uma potência (ou grupo de potências) externa à região ou uma guerra proxy 5 incentivada por tal potência. Além disso, a Amazônia é uma região estratégica ${ }^{6}$ para a defesa e a garantia da estabilidade de vários países, destacando-se aqui a Bolívia, por ser esta primordial para a integração física sul-americana.

Dessa maneira, o presente artigo busca aprofundar a discussão sobre a segurança e a defesa na América do Sul, sob um prisma regional. Ademais, procura-se aqui expor a importância de uma visão sobre a Amazônia no âmbito da defesa, dando foco não apenas às "novas ameaças"7, mas também às ameaças tradicionais. Este trabalho justifica-se devido à existência de vários problemas na região amazônica (baixa presença estatal, vazio demográfico, ação de grupos paramilitares, baixo desenvolvimento, entre outros) e à necessidade de se criar uma estratégia de segurança amazônica de cunho regional (e não sub-regional). A metodologia utilizada inclui a revisão bibliográfica de literatura especializada sobre segurança sul-americana e sobre características físicas da Amazônia, bem como a análise de mapas e de documentos emitidos pelo governo federal.

$\mathrm{Na}$ segunda seção deste trabalho, serão apresentadas características do subcontinente sul-americano em matéria de defesa e segurança. Tal caracterização será feita sob a luz da Teoria dos Complexos Regionais de Segurança (TCRS), elaborada por Barry Buzan e Ole Wæver (2003). Na terceira seção, apresentaremos o primeiro fator que torna a Amazônia uma região significativa para a defesa e a segurança da América do Sul: a propensão que ela tem de ser o principal alvo de uma invasão ou guerra proxy, conforme dito por Cepik, Oliveira e Brites (2013). A apresentação desse ponto se dará através da criação de dois cenários alternativos: um no qual há uma pequena

\footnotetext{
${ }^{4}$ Aqui, os conceitos de Amazônia e Pan-Amazônia são tidos como sinônimos, utilizando-se a ideia de Mattos (1979), ou seja, a de que "as palavras Amazônia e Pan-Amazônia deveriam simbolizar a mesma imagem geográfica. (...) Esta imensa região natural, portadora de ecologia uniforme, abrangendo o território de seis países tributários" (MATTOS, 1979, p. 22).

5 "Guerra proxy" ou "guerra por procuração" é um conflito armado no qual uma ou mais nações se utilizam de outros países para lutarem entre si.

${ }^{6}$ Neste trabalho, o conceito de "estratégico" é dado como uma característica de algo que indica que este pode ser utilizado por um Estado para ajudá-lo no combate e, assim, a executar o propósito da guerra, derivado da definição de "estratégia" apresentada por Clausewitz e utilizado por Echevarria (2007), que seria "o uso de combates para a execução do propósito da guerra" (ECHEVARRIA, 2007, p .133).

7 "Fenômenos ou ameaças de caráter não militar que desafiam ou criam problemas para a segurança dos Estados" (ISHIDA, 2007, p. 2).
} 
possibilidade de invasão ou conflito desse tipo e outro no qual há um risco iminente de haver uma invasão ou conflito, ou há uma existência efetiva destes. Na quarta seção, analisa-se o segundo fator, qual seja, o de que a Amazônia é estratégica para a garantia da estabilidade da Bolívia. Destaca-se aqui a Bolívia por ela ser um dos Estados mais importantes para a viabilização da integração infraestrutural sul-americana, analisandose, nesse caso, as ideias elaboradas por Mackinder (1904), Travassos (1935), Jaeger (2013), dentre outros. Após isso, serão apresentadas as considerações finais desta pesquisa, junto com propostas para o aumento da cooperação em segurança e defesa na América do Sul.

\section{Características da defesa e da segurança na América do Sul}

Barry Buzan e Ole Wæver (2003) caracterizam a América do Sul como um Complexo Regional de Segurança (CRS). Segundo os autores, um CRS é "um grupo de unidades cujo maior processo de securitização, dessecuritização ou ambos é tão interligado que seus problemas de segurança não podem ser razoavelmente analisados ou resolvidos separados um do outro" (BUZAN; WÆVER, 2003, p. 44).

Na mesma obra, os autores afirmam que a América do Sul seria "um CRS-padrão marcado por tensões sociais domésticas e instabilidade política, rivalidades regionais e spill over transnacional e intervencionismo de grandes potências, principalmente americano" (BUZAN; WÆVER, 2003, p. 309). Além disso, os problemas de segurança seriam fruto da baixa capacidade do Estado de se fazer presente na totalidade de seu território e de garantir a sua estabilidade. Essa questão se traduz tanto para as chamadas "novas ameaças" (crime organizado, ação de grupos paramilitares, biopirataria, dentre outras) quanto para as ameaças tradicionais (representadas por Estados).

Além dessa deficiência dos Estados em prover a segurança nos seus territórios, a América do Sul também é caracterizada pela ausência de grandes potências entre os países que a formam; é uma região multipolar com baixo grau de polarização e que possui uma baixa capacidade de interação (infraestrutura tecnológica e social para transportes e comunicação) entre seus países (CEPIK, 2005). Além de encontrar-se longe dos grandes conflitos internacionais, o complexo é marcado por baixos gastos em 
defesa: de acordo com o IISS (2014), o subcontinente ficou em penúltimo lugar, estando à frente apenas da África Subsaariana.

Dessa forma, apesar de ser uma região caracterizada pela ausência de conflitos interestatais de longa duração, a América do Sul não está livre de tensões. Na verdade, historicamente, o subcontinente é marcado por desentendimentos entre os Estados que o compõem. Como afirma Medeiros Filho (2014),

\footnotetext{
pode-se dizer que, até a década de 1970, as relações entre Estados na América do Sul ocorriam sob o pano de fundo de uma geopolítica de contenção, caracterizada pela desconfiança mútua entre os vizinhos - vistos como ameaças latentes e inimigos em potencial - e pela percepção de fronteiras enquanto instrumentos de separação (MEDEIROS FILHO, 2014, p. 32).
}

Além disso, segundo Alves (2009), até o início da década de 1980, havia uma visão do Brasil como um país imperialista, a qual impediu que se discutisse mais profundamente a questão da integração física na região amazônica ao ser firmado o Tratado de Cooperação Amazônica (TCA) ${ }^{8}$. Como afirma Medeiros Filho (2014), tal fase, denominada de "contenção", só começou a ser superada com a aproximação entre Brasil e Argentina, na década de 1980. E na década de 1990 inicia-se a fase de "cooperação", no qual são criados e institucionalizados mecanismos de cooperação regional (como o Mercosul).

No entanto, apesar de a cooperação entre os Estados sul-americanos em vários âmbitos ter crescido desde a década de 1990, o complexo ainda é marcado por certos desentendimentos, com a dinâmica e a intensidade dessas tensões variando de região para região. Prova dessa variação é o contraste entre o Cone Sul e a sub-região AndinoAmazônica. 0 primeiro é a sub-região onde o nível de cooperação é mais alto, considerada por alguns como estando perto de tornar-se uma comunidade de segurança. Já a segunda, também chamada de Amazônia ou Pan-Amazônia, abriga a maior parte dos conflitos sul-americanos.

\footnotetext{
8 Tratado firmado entre os países amazônicos (Bolívia, Brasil, Colômbia, Equador, Guiana, Peru, Suriname e Venezuela) a 3 de julho de 1978. Ele surgiu de uma política brasileira voltada para a integração regional, a fim de que fosse preservada a soberania dos Estados sul-americanos sobre a Amazônia ante as ameaças de internacionalização desta - ideia exposta, entre outros autores, por Mattos (1979).
} 
Além de marcada pela presença das novas ameaças, a Amazônia é a região que mais apresenta tensões interestatais. Teixeira e Anselmo (2011) identificam cinco principais desentendimentos nessa região: 1) Equador e Peru - relacionado com questões territoriais (tendo escalado a uma guerra aberta, em 1995); 2) Equador, Venezuela e Colômbia - relacionado a uma suposta invasão territorial por parte da Colômbia ao território do Equador para capturar um guerrilheiro das Forças Armadas Revolucionárias da Colômbia (Farc), o que também gerou um temor na Venezuela, fazendo com que Equador e Venezuela enviassem seus exércitos para a fronteira com a Colômbia; 3) Chile e Peru - relacionado à divisa marítima entre eles; 4) Chile e Bolívia relacionado a uma saída para o mar almejada pela Bolívia; 5) movimentos fronteiriços entre o Brasil e a Bolívia. Além disso, ainda poderíamos incluir uma sexta tensão: entre Venezuela e Guiana, também relacionada a questões territoriais. Além disso, a dinâmica da região ainda é agravada com a presença norte-americana sobretudo na Colômbia e no Peru. Essas relações bilaterais com a grande potência geram "desconfianças sobre as reais motivações a respeito do envolvimento dos EUA na região da floresta amazônica" (TEIXEIRA; ANSELMO, 2011, p. 23). Também não se pode esquecer da presença britânica, através de sua influência política na Guiana (pertencente à Commonwealth), e da França, através da Guiana Francesa. Assim, a Amazônia se faz uma região de grande importância para a defesa e a segurança de todo o subcontinente.

\section{A Amazônia e os problemas de defesa e segurança da América do Sul}

A região amazônica padece de vários problemas estruturais, como a baixa presença estatal na região, o que permite o fortalecimento de grupos paramilitares e do crime organizado, dentre outros problemas; a falta de infraestrutura integradora aos centros nacionais e aos centros regionais; o baixo desenvolvimento socioeconômico; e a pequena densidade demográfica - segundo Fagundes (2014), ela abriga apenas 0,3\% da população mundial (o que faz com que seja uma das regiões menos habitadas do mundo).

Outra questão é que os crimes transnacionais citados misturam-se às tensões interestatais, criando um clima de desconfiança mútua entre os Estados amazônicos. Ademais, a presença de potências extrarregionais nessa região, como os Estados Unidos 
- principalmente através do Plano Colômbia ${ }^{9}$-, é outro fator que torna a Pan-Amazônia uma região conflituosa, como dito anteriormente. Isso porque a percepção da presença dos Estados Unidos nessa região varia entre extremos - o que fica claro ao analisarem-se os planos de defesa da Colômbia e da Venezuela. Tais visões extremadas aumentam a dificuldade de uma maior cooperação entre os Estados, como afirmam Marques e Medeiros Filho (2014), segundo os quais,

neste ponto, os projetos da Colômbia e da Venezuela são inconciliáveis. A Colômbia defende e preza a parceria com os Estados Unidos, que vem lhe permitindo restabelecer o controle sobre seu território, e não pretende abrir mão da ajuda financeira e militar norte-americana. A Venezuela vê o Plano Colômbia como uma ingerência externa nos assuntos latino-americanos e uma ameaça ao país, tendo em vista que os norte-americanos estariam usando a presença na Colômbia para tentar desestabilizar o governo venezuelano e apropriar-se de suas riquezas minerais e naturais (MEDEIROS FILHO, 2014, p. $55)$.

Assim, devido à conjugação de todos esses problemas existentes na Amazônia, pode-se afirmar que essa é a região sul-americana que possui a maior probabilidade de sofrer uma invasão territorial por parte de uma potência extrarregional ou uma guerra proxy (utilizada para desestabilizar o subcontinente). Essa afirmação envolve a criação de dois cenários: um primeiro, caracterizando-se por uma probabilidade menor de que haja uma invasão ou uma guerra desse tipo; um segundo, caracterizando-se pelo risco iminente ou por uma efetiva invasão territorial ou guerra proxy.

No primeiro caso, a região amazônica adquire uma importância em termos de segurança. Isso porque os problemas presentes na região (fundamentalmente as novas ameaças), que a tornariam mais propícia a uma ingerência extrarregional, ameaçam o bem-estar tanto dos Estados amazônicos quanto do restante da América do Sul. Visto que essas novas ameaças caracterizam-se por seu caráter transnacional, elas acabam por espalhar-se para outras sub-regiões sul-americanas.

\footnotetext{
${ }^{9}$ Acordo entre a Colômbia e os Estados Unidos que "envolve a transferência de grande quantidade de equipamentos militares no reforço das forças armadas colombianas para o combate dos movimentos guerrilheiros e traficantes de droga que atuam no país, além de treinamento, assessoria militar e ajuda financeira para manutenção das operações" (TEIXEIRA; ANSELMO, 2011, p. 23).
} 
Já no segundo caso, a região pan-amazônica adquire importância em termos de defesa do subcontinente sul-americano. Isso porque, com uma invasão ou uma guerra proxy efetiva ou com o risco iminente de que elas venham a ocorrer (juntas ou não), a Amazônia configura-se como uma área estratégica para preservar a segurança do subcontinente. Segundo Cepik, Oliveira e Brites (2013), no caso de uma potência extrarregional resolver atacar a América do Sul em duas frentes - uma no continente (pela própria Amazônia) e outra no Atlântico Sul -, a fim de se apossar do pré-sal brasileiro, por exemplo, o aumento do contingente de tropas na Amazônia reduziria as chances de que tal cenário viesse a ocorrer.

Além disso, Oliveira (2013) expõe a ideia de uma "estratégia de defesa em camadas" na América do Sul, a fim de garantir a defesa tanto do subcontinente quanto do pré-sal. Nessa estratégia, que inclui três linhas de defesa, a mais interior seria localizada no Heartland ${ }^{10}$ sul-americano, que inclui o centro-sul amazônico. A segunda linha ficaria no litoral brasileiro, e a terceira, nas ilhas pertencentes ao Brasil. Cepik, Kerr e Brites (2013) afirmam que, para a execução dessa estratégia, é essencial a instalação de bases militares (por parte do Brasil) no Heartland do subcontinente - na localização sob jurisdição brasileira. Nesse caso, a instalação dessas bases localizadas no centro-sul da Amazônia possibilitaria que o Brasil, em conjunto com outros Estados sulamericanos, apoiasse a defesa da Amazônia contra uma invasão promovida por uma potência agressora. Essas bases também poderiam servir para levar, de maneira relativamente rápida e eficiente, efetivos e armamentos a fim de que o país pudesse defender-se contra uma guerra proxy incentivada por uma potência extrarregional ou para defender um aliado seu que fosse atacado. Assim, a Amazônia seria estratégica para o Brasil e para os demais países sul-americanos, caso estes venham a deparar com ameaças como as descritas.

\section{Mapa 1: Geopolítica do pré-sal: mapa das linhas interiores de defesa}

\section{baseada no coração do Brasil}

\footnotetext{
10 Esse conceito foi desenvolvido pelo geógrafo Halford John Mackinder. Segundo ele, o Heartland seria uma região com "condições de mobilidade de poder militar e econômico de caráter de longo alcance, ainda que limitada” (MACKINDER, 1904, p. 11). Essa região também se caracterizaria por oferecer fácil projeção em diversas direções, por estar posicionada no centro de uma grande massa continental e por apresentar características geográficas de uma fortaleza natural rodeada por grandes acidentes geográficos. Para Mackinder, o Heartland estaria localizado, aproximadamente, na atual região do Leste Europeu.
} 


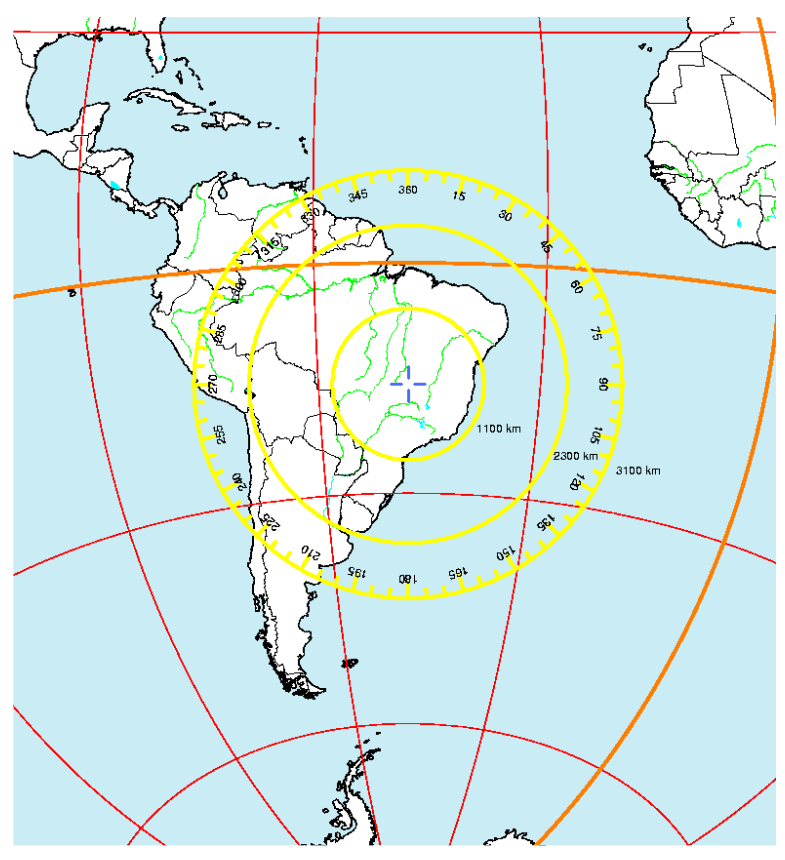

Fonte: OLIVEIRA, 2012.

Ademais, no caso de uma invasão territorial ou na hipótese de uma guerra proxy, a região da Pan-Amazônia poderia atuar como um teatro de uma guerra irregular ${ }^{11}$. Isso decorre do fato de que "os ambientes operacionais de selva (...) são aqueles que lhes proporcionam [às forças irregulares] as mais significativas vantagens, porque restringem as capacitações científico-tecnológicas do oponente com o maior poder de combate" (PINHEIRO, 2013, p. 9-10). É interessante ressaltar que tal formato de guerra já é uma realidade para o pensamento estratégico das Forças Armadas brasileiras. Isso se verifica na existência de organizações militares treinadas para agir nesse tipo de conflito - como o Centro de Instrução de Guerra na Selva (CIGS) - e na própria formulação da Estratégia Nacional de Defesa (END), segundo a qual

os imperativos de flexibilidade e de elasticidade culminam no preparo para uma guerra assimétrica, sobretudo na região amazônica, a ser sustentada contra inimigo de poder militar muito superior, por ação de um país ou de uma coligação de países que insista em contestar, a pretexto de supostos interesses da Humanidade, a incondicional soberania brasileira sobre a sua Amazônia (BRASIL, 2008, p. 27).

11 "Conflito conduzido por uma força que não dispõe de organização milita formal" (VISACRO, 2009 apud SOUZA, 2014, p. 35). Entretanto, é importante ressaltar que tal formato de guerra tem sido incorporado pelo Exército de vários países. 


\section{A Amazônia e a estabilidade e a defesa da Bolívia}

A Amazônia também adquire um caráter de importância para a defesa e a segurança da América do Sul devido à sua localização estratégica. Sabe-se que o centrosul da Pan-Amazônia encontra-se no interior do subcontinente. Desse modo, essa região é de grande importância para a garantia da estabilidade e da defesa do território de vários Estados sul-americanos. Dentre os territórios que mais se destacam está o da Bolívia. A importância dada a esse país aqui se deve à significância deste para a integração física sul-americana, principalmente devido a sua posição no subcontinente.

Ao operacionalizar o conceito de Heartland na América do Sul, Oliveira e García (2010) estabeleceram-no numa região que incluiria parte da Amazônia, o território paraguaio, o norte da Argentina e a maior parte da Bolívia. Dentre as características que fariam dessa região o Heartland sul-americano, Oliveira (2013) destaca algumas: o grande potencial integrador com outras partes da América do Sul, pois "inclui em sua delimitação a área de abrangência das bacias hidrográficas sul-americanas, vitais para a integração hidroenergético-hidroviária do continente" (OLIVEIRA, 2013, p. 6). Além, disso, "esta zona também se mostra região-chave para a construção de capacidades defensivas e industriais para que o Brasil [e outros Estados sul-americanos] possa defender sua soberania sobre (...) a Amazônia" (OLIVEIRA, 2013, p. 6). Assim, o fato de a Bolívia fazer parte do Heartland sul-americano atesta desde já a sua importância sobre a integração infraestrutural sul-americana.

\section{Mapa 2: 0 Heartland da América do Sul e as macrorregiões do continente}




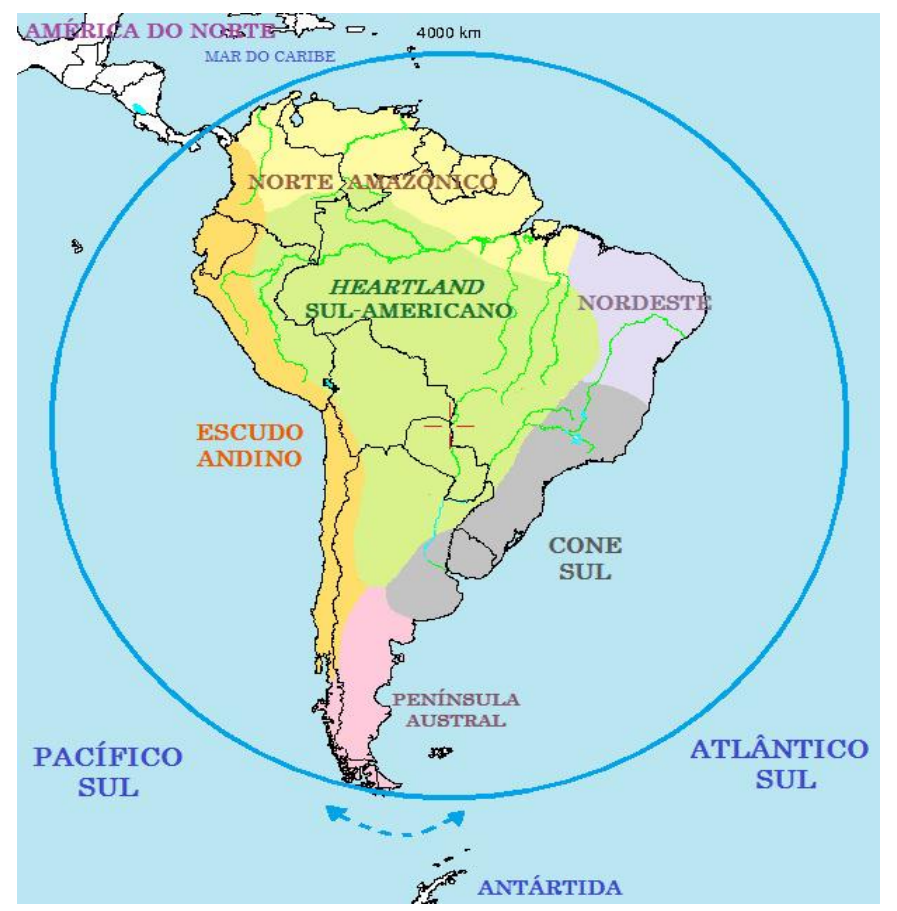

Fonte: OLIVEIRA E GARCÍA, 2010.

Esse Estado inclusive já foi tratado como o Heartland do subcontinente (TRAVASSOS, 1935). Segundo ele, a Bolívia possuiria uma série de características geográficas que fariam com que seu território fosse o mais importante da América do Sul. Dentre essas características, podemos citar as mais importantes. Primeiramente, há dois "antagonismos" fundamentais no continente sul-americano: entre o Atlântico e o Pacífico e entre a bacia amazônica e a bacia platina. A Bolívia seria o Estado que agrupa esses antagonismos devido à sua localização em relação aos três grandes acidentes geológicos da América do Sul: a cordilheira dos Andes, que divide o continente em leste e oeste, e as próprias bacias do Amazonas e do Prata, que condicionam uma divisão norte-sul (SEVERO, 2012). Nesse sentido, o território boliviano conecta as vertentes do oceano Pacífico e do oceano Atlântico e as bacias amazônica e platina. Para Travassos, "as tensões sobre o território boliviano estavam concentradas na área situada entre as cidades de Santa Cruz de la Sierra, Cochabamba e Sucre. Existia entre essas cidades um 'triângulo estratégico', que incluía as importantes cidades mineradoras de Oruro e Potosí" (TRAVASSOS, 1935 apud SEVERO, 2012, p. 4).

Embora as ideias desse autor se referissem a uma estratégia para neutralizar a presença argentina na Bolívia e garantir uma posição de preponderância do Brasil sobre a América do Sul, alguns pontos delas são operacionalizáveis. Nesse caso, as características do território boliviano, apresentadas por Travassos (1935), poderiam ser 
utilizadas para a intensificação do processo de integração infraestrutural sul-americana. Assim, visto que a Bolívia é ponto de conexão entre o Atlântico e o Pacífico e entre as duas maiores bacias hidrográficas do subcontinente, seu território poderia ser utilizado para uma integração norte-sul e leste-oeste. É interessante notar que a Bolívia já possui uma importante atuação em projetos existentes que pretendem ligar os dois oceanos. É o caso do Eixo Interoceânico Central (EIC), um dos projetos prioritários da Iniciativa para a Integração da Infraestrutura Sul-Americana (IIRSA) ${ }^{12}$.

Além disso, também é válido ressaltar que, no âmbito da IIRSA, “o território boliviano se torna um ponto central na interconexão de diferentes corredores, recebendo nada menos que cinco eixos de integração dos nove já em execução" (PFRIMER, 2011, p. 138). Ademais, a integração energética da Bolívia com outros países sul-americanos já se mostrou viável, como no caso do gasoduto Brasil-Bolívia (Gasbol).

Vale a pena destacar aqui que, conforme indica Jaeger (2014), a integração infraestrutural produz impactos sobre a segurança de um país ou região. Primeiramente, esse tipo de integração pode influenciar a segurança interna de cada Estado, através dos efeitos que esta possui no desenvolvimento de suas regiões. Uma integração que conecte áreas periféricas a centros econômicos e que escoe a produção de áreas marginalizadas pode servir para melhorar o bem-estar da população dessas zonas, diminuindo consideravelmente os riscos de sublevação e, portanto, de desestabilização. Além disso, o desenvolvimento destas fará com que sua densidade demográfica aumente, contribuindo para impedir que o vazio demográfico em regiões como a própria Amazônia cause mais problemas a essas localidades (JAEGER, 2014).

Além disso, a integração regional poderia diminuir os riscos de instabilidade social em casos de catástrofes ambientais, através da construção de estradas e pontes que servissem de infraestrutura crítica ${ }^{13}$ (JAEGER, 2014). Essas estruturas também podem ajudar a impedir a presença de uma potência extrarregional na América do Sul, visto que "a prevenção de desastres naturais também pode servir de justificativa para a

\footnotetext{
12 "A IIRSA é o foro técnico para temas relacionados com a planificação da integração física regional sulamericana do Conselho Sul-Americano de Infraestrutura e Planejamento (Cosiplan) da União de Nações Sul-Americanas (Unasul)" (IIRSA, 2012).

13 Segundo o Guia de Referência para a Segurança das Infraestruturas Críticas da Informação do Gabinete de Segurança Institucional da Presidência da República do Brasil, infraestrutura crítica são "instalações, serviços e bens que, se forem interrompidos ou destruídos, provocarão sério impacto social, econômico, político, internacional ou à segurança nacional".
} 
instalação de infraestrutura estrangeira com objetivos estratégicos" (JAEGER, 2014, p. 36), como é o caso da presença militar norte-americana no Paraguai que permitiu, através de um acordo bilateral, o estabelecimento de um Centro Operacional de Emergências Regionais e de um Depósito de Ajuda Humanitária, que são monitorados pelo U.S. Southern Command (SOUTHCOM), em uma localidade estratégica no leste do Paraguai. Ademais, a infraestrutura de integração regional também pode servir de modo similar à logística nacional, no que se refere à defesa de um Estado ou de uma região. Isso porque a mesma infraestrutura que serve para conectar economicamente os Estados sul-americanos pode servir para levar efetivos militares, armamentos e até suprimentos caso um Estado tenha a sua segurança ameaçada. Assim, essa logística pode ajudar na consecução da estratégia de defesa em camadas, apresentada na seção anterior (JAEGER, 2014).

Portanto, ao mesmo tempo em que garante a defesa e a estabilidade da Bolívia, pelo fato de o território desse Estado localizar-se dentro dela, a Amazônia também garante a defesa da integração infraestrutural sul-americana, devido à importância que o Estado boliviano tem para tal processo. E, como visto, tal processo tem várias implicações para a garantia da segurança do subcontinente. Esse fato atesta mais uma vez a importância da Amazônia para a segurança e para a defesa do Complexo Regional Sul-Americano.

\section{Considerações finais}

O presente trabalho analisou as implicações que as dinâmicas da região amazônica têm para a defesa e para a segurança de todo o subcontinente sul-americano. Essa análise deu-se sob a luz de dois pontos fundamentais: primeiramente, que a PanAmazônia é a localidade da América do Sul que mais possui propensão a sofrer uma invasão territorial devido aos problemas estruturais que ali se encontram. Esse primeiro ponto divide-se em dois cenários alternativos: no primeiro cenário, há apenas uma possibilidade remota de ingerência extrarregional. Nesse caso, os problemas da região ameaçam a estabilidade dos Estados, ao criar condições para que se desenvolvam as novas ameaças. Nesse sentido, a Amazônia é importante para a segurança dos Estados sul-americanos. Já no outro cenário, temos uma invasão ou risco iminente de invasão territorial por parte de uma potência extrarregional agressora ou de uma guerra proxy, 
incitada por tal potência ou grupo de potências. Nesse caso, temos um problema de defesa, já que há uma grande ameaça ao estado de segurança da América do Sul. Nesse cenário, a Amazônia é estratégica para os Estados sul-americanos por poder constituir uma das linhas de defesa do subcontinente e por funcionar como um teatro para uma guerra irregular.

O segundo ponto que guiou este trabalho ressalta a importância da Amazônia, por ela possuir uma localização estratégica para assegurar a defesa da Bolívia. Ao garantir a manutenção do estado de segurança no território boliviano, a Amazônia está agindo para zelar pela integração sul-americana, pois a Bolívia é altamente estratégica para que de fato ocorra uma integração física regional, já que está incorporada ao Heartland sul-americano e reúne em seu território os dois "antagonismos" citados por Mário Travassos (1935) que caracterizam a América do Sul: oceano Atlântico e oceano Pacífico, bacia do Amazonas e bacia do Prata.

Com a elaboração deste trabalho, pode-se constatar não apenas o papel central que a Amazônia possui na defesa e na segurança sul-americanas, mas também a necessidade de uma estratégia de defesa regional a fim de que todos os Estados possam agir de forma coordenada em caso de uma ingerência extrarregional. Dessa maneira, é necessário o aprofundamento dos mecanismos institucionais de cooperação em defesa, como o Conselho de Defesa Sul-Americano (CDS) ${ }^{14}$, e que novos sejam criados. Seguindo essa linha, também é importante que os debates na Organização do Tratado de Cooperação Amazônica (OTCA) sobre a defesa e a segurança amazônicas sejam intensificados, revitalizando, assim, essa organização. Além do aprofundamento desses mecanismos, também é importante que a integração infraestrutural seja intensificada. Essa integração pode servir como base física para uma coordenação em defesa entre os Estados do subcontinente.

\section{Referências Bibliográficas}

ALVES, Camila Bezerra. A Integração Regional e a Dessecuritização da Amazônia. Porto Alegre, RS. Trabalho de Conclusão de Curso (Bacharelado em Relações Internacionais) Faculdade de Ciências Econômicas, UFRGS, 2009.

\footnotetext{
14 Mecanismo criado em 2008, no âmbito da Unasul, cujos objetivos são a coordenação das políticas de defesa dos países sul-americanos e a criação de uma identidade estratégica e de uma base industrial de defesa no âmbito regional.
} 
BRASIL. Estratégia Nacional de Defesa. Brasília: Ministério da Defesa, 2008.

BUZAN, Buzan; WÆVER, Ole. Regions and Powers: The Structure of International Security. 1aㅡ edição. Cambridge, UK: Cambridge University Press, 2003.

CEPIK, Marco Aurélio Chaves. Segurança na América do Sul: Traços Estruturais e Dinâmica Conjuntural. Análise de Conjuntura OPSA, Rio de Janeiro, Vol. 9 No. 9, p. 1-11, 2005.

CEPIK, Marco Aurélio Chaves; Oliveira, Lucas Kerr de;. BRITES, Pedro Vinícius Pereira. 0 Pré-Sal e a Segurança do Atlântico Sul: A Defesa em Camadas e o Papel da Integração Sul-Americana. Revista da Escola de Guerra Naval, Rio de Janeiro, Vol. 20, No. 1, p. 139$164,2014$.

ECHEVARRIA II, Antulio J. Clausewitz and Contemporary War. 1aㅡ edição. Oxford, UK: Oxford University Press, 2007.

FAGUNDES, Flávia Caroline de Resende. Cooperação em Segurança e Defesa no Espaço Andino-Amazônico: Ambiguidades e Potencialidades. Porto Alegre, RS. Dissertação (Mestrado em Relações Internacionais) - Faculdade de Ciências Econômicas, UFRGS, 2014.

IIRSA. IIRSA en COSIPLAN. Disponível em: $<$ www.iirsa.org/Page/Detail?menuItemId=27>; acessado em 3 de agosto de 2015.

IISS. Military Balance 2015. London, UK: IISS, 2014.

ISHIDA, Eduardo. Política de Segurança Integrada da Amazônia. Artigo apresentado no Colóquio Amazônia e o Pacífico Sul-Americano e sua Importância para o Brasil, UNESP, São Paulo, SP, 2007.

JAEGER, Bruna Coelho. A Estratégia Infraestrutural da Integração Sul-Americana: A Geopolítica do Eixo Interoceânico Central. In: MAZZA, Silvia Matilde; MILANO, Alicia María Francisca. Ciencia para el Desarrollo de los Pueblos. Corrientes, Argentina: Universidad Nacional Del Nordeste, 2013.

JAEGER, Bruna Coelho. Integração Infraestrutural Sul-Americana: Impactos sobre a Geopolítica e a Estratégia Regional. Porto Alegre, RS. Trabalho de Conclusão de Curso (Bacharelado em Relações Internacionais) - Faculdade de Ciências Econômicas, UFRGS, 2014. 
MACKINDER, Halford John. The Geographical Pivot of History. The Geographical Journal. UK, Vol. 23 No. 4, p. 421-437, 1904.

MAGALHÃES, Diego Trindade d'Ávila. Comunidade de Segurança: A Teoria no Conceito. Carta Internacional, Belo Horizonte, MG, Vol. 7 No. 2, p .81-98, 2012.

MARQUES, Adriana A.; MEDEIROS FILHO, Oscar. Entre a "Segurança Democrática" e a "Defesa Integral": Uma Análise de duas Doutrinas Militares no Canto Noroeste do Subcontinente Sul-Americano. In: NASSER, Reginaldo Mattar; MORAES, Rodrigo Fracalossi. (Orgs.). O Brasil e a Segurança no seu Entorno Estratégico. 1ạ edição. Brasília, DF: IPEA, 2014.

MATTOS, Carlos de Meira. Uma Geopolítica Pan-Amazônica. Rio de Janeiro, RJ: BIBLIEX, 1979.

MEDEIROS FILHO, Oscar. Cenários Geopolíticos e Emprego das Forças Armadas na América do Sul. São Paulo. Dissertação (Mestrado em Geografia), USP, 2004.

MEDEIROS FILHO, Oscar. Breve Panorama de Segurança na América do Sul. In: NASSER, Reginaldo Mattar; MORAES, Rodrigo Fracalossi. (Orgs.). O Brasil e a Segurança no seu Entorno Estratégico. 1a edição. Brasília, DF: IPEA, 2014.

OLIVEIRA, Lucas Kerr de; GARCIA, Tatiana de Souza Leite. O Conceito de Heartland na Geopolítica Clássica: Funcionalidade e Limites para a Análise da Região Central da América do Sul. Artigo apresentado no GT 17 - Energia e Meio Ambiente da ANPPAS, Florianópolis, SC, 2010.

OLIVEIRA, Lucas Kerr de. A Geopolítica Clássica e as Novas Geopolíticas: Perspectivas para a Defesa da Amazônia, do Pré-Sal e da Integração Regional Sul-Americana. Artigo apresentado na I Reunião Temática do Centro de Estudos Estratégicos do Exército Brasileiro: Novas Geopolíticas e a Pan-Amazônia, Brasília, DF, 2013.

PINHEIRO, Álvaro de Souza. O Conflito de 4⿳亠丷厂 Geração e a Evolução da Guerra Irregular, Coleção Meira Mattos: Revista das Ciências Militares, Rio de Janeiro, RJ, No. 16, p. 16-33, 2007.

PFRIMER, Matheus Hoffmann. Heartland Sul-Americano? Dos Discursos Geopolíticos à Territorialização de um Novo Triângulo Estratégico Boliviano. GEOUSP: Espaço e Tempo, São Paulo, SP, No. 29, p. 131-144, 2011.

RODRIGUES, Bernardo Salgado. O Heartland Sul-Americano: A Importância Geopolítica da Bolívia para a América do Sul. OIKOS, Rio de Janeiro, RJ, Vol. 13 No. 1, p. 40-56, 2013. 
SEVERO, Luciano Wexell. A Importância da Bolívia e a Integração da América do Sul. Artigo apresentado no Painel Região Andina: Entre a Coesão Interna e os Interesses Extrarregionais da ABRI, Brasília, DF, 2012.

SOUZA, Marcelo Bastos de. Guerra Irregular no Contexto da Estratégia de Resistência. Rio de Janeiro, RJ. Dissertação (Mestrado em Ciências Militares). ECEME, 2014.

TEIXEIRA, Vinicius Modolo; ANSELMO, Rita de Cássia Martins de Souza. Integração e Conflitos na América do Sul: A Fronteira Amazônica. Revista de Geopolítica, Uberlândia, MG, Vol. 2, p. 57-76, 2011. 